\title{
The Design and Implementation of the Examination and Approval System of Executive Professional Rules in Open Education
}

\author{
Yang Zhao * \\ Science and Technology and Development Planning Office \\ Yunnan Open University \\ Kunming, China \\ 42755044@qq.com
}

\begin{abstract}
The Executive Professional Rules are the basic documents of managing and carrying out credit recognition for standardized professional teaching process, which are independently selected by learners, formulated by branch campuses and submitted to provincial Open University for review. The branch campuses of provincial open universities spread over the whole province. Because the number of students is large, the course data of the selected majors is disordered, and the traditional manual examining method has a heavy workload, low efficiency and high error rate, many students can't graduate on time. Under this background, the author designed and developed an examination and approval system using the network version of $B / S$ structure, which improves the examination quality and efficiency, and not only standardizes the teaching management, but also ensures the learners to complete their studies smoothly. After this system was used, in the process of graduation examination, the number of students in Yunnan Open University who can't graduate on time due to mistakes in course selection reduced about $95 \%$.
\end{abstract}

Keywords-Open Education; Executive Professional Rules; Examination and Approval System; Systematic Design

\section{INTRODUCTION}

The Professional Rules are important documents to ensure educational quality and talents cultivating specifications in open university, and also basic gist of organizing teaching process and assigning teaching tasks, basic instruction of the operation of open university courses platform, and courses selection rules for learners, including cultivating targets and specifications, courses modes setting rules, courses setting rules, graduation rules and related explanation[2].. The Professional Rules are open, emphasizing mutual recognition of courses and resource sharing, implementing a complete credit system and reflecting learners' independent choice.

\section{PROFESSIONAL RULES AND ITS HiERARCHICAL MANAGEMENT}

The open university around China is responsible for the implementation of professional rules, carrying out hierarchical management. From the type and management level, it can be divided into guiding professional rules, implementing professional rules and executive professional rules.

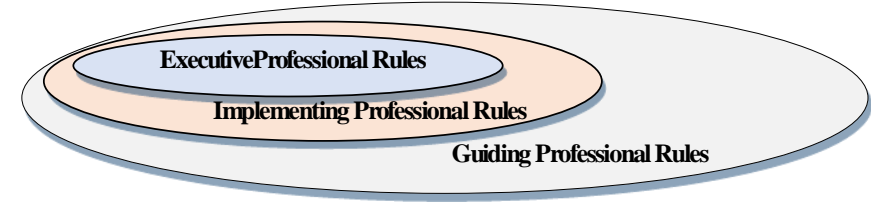

Fig.1. Hierarchical Management of Professional Rules

\section{A. Guiding Professional Rules}

The Guiding Professional Rules are formulated and issued by The Open University of China, which is a specific teaching guidance document. Besides the compulsory courses set by the Open University of China, the Guiding Professional Rules also include the elective courses of the provincial open universities nationwide, which is big course set to achieve the goal of talent cultivation, with unified professional knowledge structural requirements and individual differences.

\section{B. Implementing Professional Rules}

According to the requirements of the guiding professional rules and the actual situation of the province, the Implementing Professional Rules are provincial teaching implementing documents formulated by each provincial open university. The Implementing Professional Rules can get rid of part of the elective courses from the Guiding Professional Rules, and regulate some courses as the compulsory courses for the learners. The provincial-level open universities complete the formulation of Implementing Professional Rules and the examination of Implementing Professional Rules.

\section{Executive Professional Rules}

The Executive Professional Rules are the courses sets for learners to complete professional learning and acquire certificates. The Executive Professional Rules is made by the learners or the branch campuses, who chooses the courses independently among the provincial-level Implementing Professional Rules. The learners can not only acquire the diploma by only completing the credits required by the minimum graduation conditions, but also take other courses in the Implementing Rules according to their own needs. The branch campuses assist and manage the learners to formulate correct executive professional rules. 


\section{THE POSING OF PROBLEMS AND ANALYSIS OF NEEDS}

\section{A. Current status and problems}

In the educational administration management system of the Open University of China, the professional rules management only contains the function of starting using and checking of the implementing professional rules in provincial open universities, but does not check the executive professional rules made by branch campuses and students. However, in the real work, due to shortage of staff, meticulous and various constraints of professional rules, and deviation in understanding the professional rules, the branch campuses often make mistakes in formulating executive rules, which make students miss or choose the wrong courses after learning the specified number of years according to the wrong rules, resulting in their failure to graduate on time. In order to standardize management and avoid such kind of problems, the provincial-level open universities need to proceed manually examination and approval to a large number of executive rules of branch campuses every semester, so as to ensure that branch campuses have the correct and complete execution basis for their teaching process.

It needs a relatively long time period from issuing the Guiding Rules by the Open University of China, to formulating and issuing the Implementing Rules by provincial universities and formulating Executive Rules by the branch campuses, and to carrying out the rules after the examination and approval by the provincial university. The provincial university manually examine the Executive Rules every semester. With the expansion of enrollment and the development of flat management, the examination and approval work has a large amount of data, being time-consuming and labor-consuming with a low efficiency, and it is inevitable to make mistakes.

\section{B. Analysis of needs}

If the check with correctness and effectiveness can be finished while branch campuses are formulating the executive rules, the examination and approval process can be shortened, which can not only avoid the problem that students fail to graduate on time due to wrong or missed selection of courses, but also provide more time for later textbooks ordering, students' course selection, teaching arrangement and so on.

The Examination and approval system of the executive professional rules of the Open University is the second development of Open University educational administration system, and it plans to realize the informationization management of the delivery of implementing professional rules of provincial open universities and the branch campuses' examination and approval work of the executive rules.

This system can further strictly control the correctness of the formulation, approval and examination of the executive rules, realize the standardization and fine management of educational affairs, and avoid all kinds of educational administration problems caused by human errors; and can greatly shorten the process of formulating and approving the executive rules, improve the timeliness, and free human resources from the heavy manual examination work.

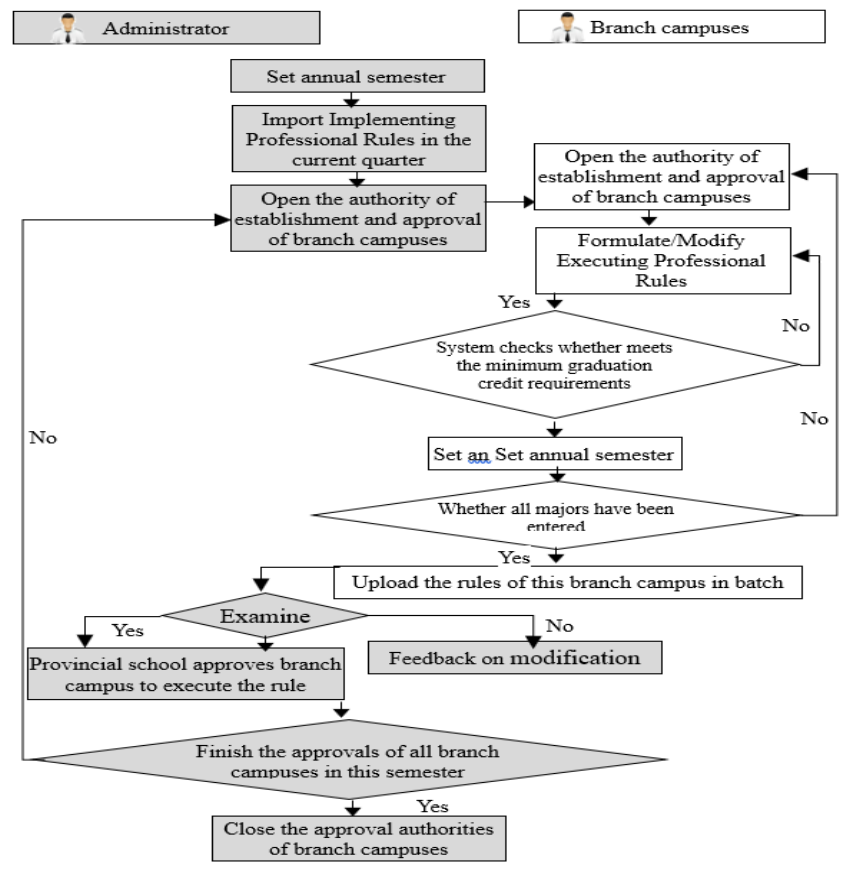

Fig.2. Systematic Business Process

\section{TECHNICAL METHOD AND BUSINESS PROCESS}

\section{A. Technical method}

In terms of functional design, the "Information management system of open education professional rules" is designed as a network version of B/S structure. The server is set up in the provincial universities. The branch campuses are accessed through the network, establishing a dynamic professional course information database with the professions as the unit and the branch campuses as the division, in order to mainly realize the information management of the delivery of the implementing professional rules of provincial universities and the examination and approval of executive rules of each branch campus. The system mainly considers the realization of standard workflow, effective process control constraints, and the generation and examination of efficient and error-free rigid documents of teaching process control (that is, the executive professional rules of each major in each branch campus).

\section{B. Business process design}

Combined with the actual work, after in-depth analysis of the previous professional rule management work, the examination system is designed in terms of the correctness of rule formulation, standardization of management work, efficiency and rigor of business flow, and its main business process is shown in Fig. 2. Based on years of teaching plan and manual management workflow of professional rules, the process is comprehensively analyzed and optimized, realizing the various functions of rules distribution, formulation, reporting, examination and feedback in the process of professional rules management, and making necessary constraints on various functions, so as to realize comprehensive information management. 


\section{SYSTEM FUNCTION AND TECHNICAL REALIZATION}

The main framework of the system is divided into authority management, provincial-level implementing professional rules management, branch-campuses-level professional rules management, data import and export, backup statistics and other parts. Among them, the main function of the system is to formulate, submit, examine, give feedback and archive executive professional rules. The main functions are:

\section{A. Authority management function}

It is divided into administrator authority and branch campus authority. The administrator is generally the staff in charge of professional rules management in the provincial universities, who is responsible for allocating and managing the users of branch campuses, creating a new semester, as well as importing and exporting the provincial implementing professional rules base, rules description, implementation scheme, operation manual and documents, switching on and off the executive rules formulation and reporting functions of the users of branch campuses, examining the rules submitted by each user, and giving feedback, so as to complete the data backup. The authority of branch campuses can query provincial implementing professional rules, operation manuals, rules descriptions, implementation plans and documents, formulate executive rules, select the opening courses sets, submit executive rules to provincial universities for examination, modify the rules that are not approved, and print the approved rules.

\section{B. Management function of implementing professional rules}

Realize the coupling and association between the system and the professional rules management in the teaching administration system of the Open University of China. Administrators import and issue provincial implementing professional rules, so that all users can inquire about them.

(1) The administrator creates a new semester, sets the authority of each branch campus to formulate and report the executive professional rules, so as to realize the professional information management with the professions as the unit and the branch campuses as the division;

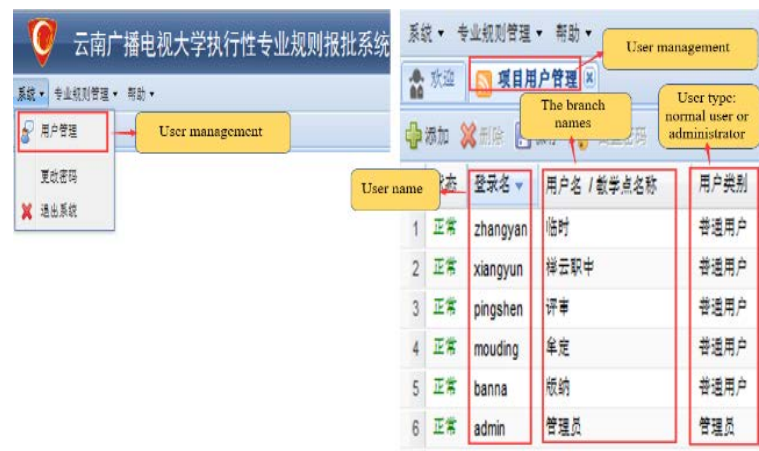

Fig.3. Authority Management

(2) Management of implementing Professional Rules base. Administrators export the implementing professional rules of each semester from the educational administration management system of the Open University of China, and after reasonable setting, they are imported into the system to form the implementing professional rules base and courses sets base, so as to help the branch campuses to formulate executive rules, choose courses, delete redundant rule..

(3) Query document base management. The administrator will import the professional rules assembly document, professional rules description, and professional implementing scheme into the system according to the professions, so as to provide document query, delete redundant documents, generate and distribute official documents and various learning manuals for userz $\mathrm{s}$ at all levels.

\section{Management function of executive professional rules}

This is the main body function part of this system, which realizes the formulation, submission, examination, feedback, printing and so on of the executive professional rules in branch campuses. The necessary constraints are made for the formulation of executive rules, so as to avoid all kinds of errors caused by the improper understanding of rules formulation policies and problems prone to appear in manual examination of branch campuses from the perspective of functional design.

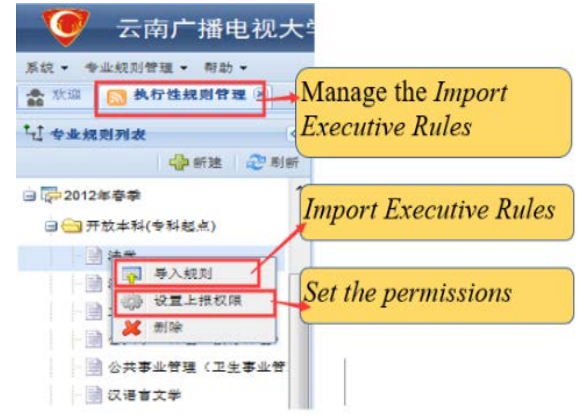

Fig.4. Import Executive Rules and Set the Submission Authority

(1) Formulating function of Executive Professional Rules. On the one hand, the system provides a unified interface for branch campuses to formulate executive rules, choose courses, and adjust the courses' semester according to the actual needs. On the other hand, the system produces constraint condition automatically based on the imported implementation rules: When the interface has been generated, the compulsory courses are set to be "specified action" automatically, and cannot be modified; and only the elective courses can be modified, so as to avoid the mistakes that students miss the required courses and cannot graduate.

(2) Verification function of the branch campuses. When the branch campuses need to save every professional rule after formulating, the system can examine according to the four necessary conditions of minimum requirements for graduation (minimum graduation credits, minimum examination credits of the Open University of China, minimum credits for each module, and minimum examination credits for each module of the Open University of China). If the requirements cannot be reached, it cannot be saved until it is modified and qualified.

(3) Submission function of branch campuses. In order to orderly control the branch campuses to report rules, the software restricts the submission function of branch campuses. Only after all rules of the current quarter are formulated and 
saved successfully, can all rules be submitted to the administrator for examination;

(4) Examination function of provincial universities. The provincial universities examine the rules submmited by the branch campuses, mainly examining whether the semester of the course is reasonable (it has been reviewed by the credit selection rationality software), so that the data of manual examination is reduced by dozens of times. After the examination, feedback of "pass" or "fail" is given, and modification suggestion for those "fail" is given;

(5) Feedback query function. The branch campuses can query the pass conditions of rules and feedback opinions;

(6) Printing function. As to the rules which passed the examination, the branch campuses can generate a PDF approval form with two-dimensional barcode for printing, and the generated approval form cannot be modified by the branch campuses. After the document is printed, it is signed and sealed for the provincial universities and branch campuses to record. As to the rules which failed the examination, the approval form cannot be generated. The branch campuses must modify the rules according to the modification suggestions and submit for examination again until it is approved.

(7) Uniqueness management. The system automatically generates two-dimensional barcode as the only identification of executive professional rules. It can be identified by scanning laser or entering two-dimensional code numbers, and then corresponding data from the system will be presented, so that the same professions of multiple branch campuses will not be mixed up.

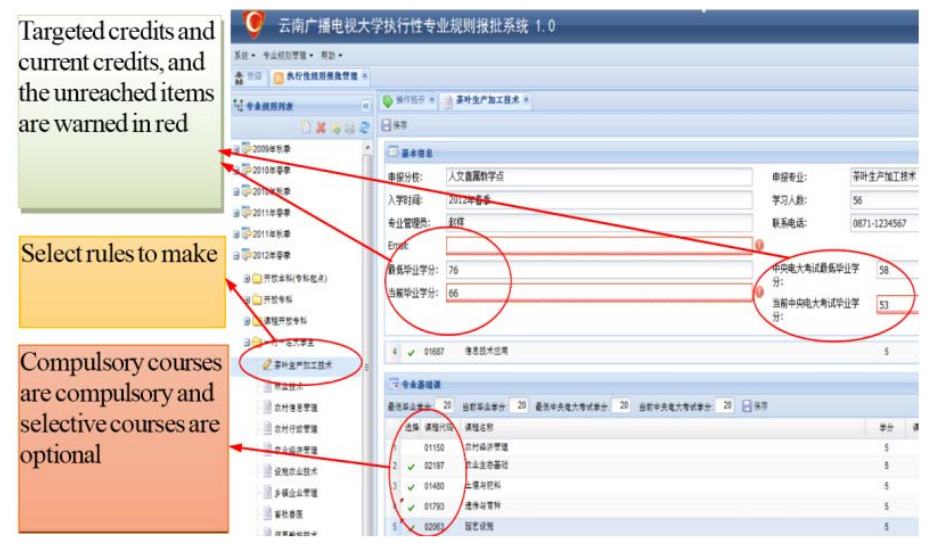

Fig.5. Implementing Rules Formulating and ExaminationInterface

\section{Import function}

Import professional rules base of each semester; import rule description, implementation plan, official document, tutorial and so on.

\section{E. Export function}

Export professional rules to make data backup and file archiving, in accordance with the condition of year, semester, rule type (executive rules/implementing rules), branch campuses and others.

\section{F. Statistical function}

Make statistics and report the details of branch campuses and executive rules; statistics and report the details of the number of majors, passed number and failed number; statistics on the total number of rules, courses, and data examination volume in each quarter, and generate various reports.

\section{CONCLUSION}

"Professional Rules Information Management System of Open Education" has been developed. After several rounds of data testing, it has been formally applied to the implementation of professional rules formulation and approval of Yunnan Open University. By the end of the autumn semester of 2018, Yunnan Open University has completed the formulation and examination of 3530 executive rules in more than 130 branch campuses across the province, involving more than 71000 students. After the systematic examination, 1897 learners' executive professional rules in 76 branch campuses were missed or mistakenly selected, and relevant management personnel have corrected the wrong professional rules in time. The comprehensive application of this system greatly shortens the working period of the approval and examination of the executive professional rules, obviously improves the accuracy of the examination work, and promotes the quality and efficiency of the management of professional rules .

The development technology of the system has advancement and general applicability, and it can be installed easily and the user interface is friendly. The function of the system can satisfy the needs of the professional rules management of the open education, and the business process design is standard and strict, and the process control is efficient and accurate. Besides, the system can be widely used in open education executive professional rules management, and can be popularized to the open universities nationwide.

\section{REFERENCES}

[1] Zhang Chao. Analysis of the Development History and Applicability of the Educational Administration Management System of the Open University of China [J]. Transmissibility Research, 2018, 2 (27): 183-184. (In Chinese)

[2] Liu Chaozong, Lin Biqun. Secondary Development and Application of Function Module of Educational Administration Management System of Open Education (CPS1.0) [J]. Journal of Fujian Radio and Television University, 2017. (In Chinese)

[3] Zhang Haipeng, Jia Jianrong. Practice and Exploration on the Construction of Teaching Support Service System in Open University [J]. Journal of Shaanxi Radio and Television University, 2015, 17 (4): 16-18. (In Chinese)

[4] Deng Mingxue. Analysis of the Current Situation and Optimization of the Educational Administration Management System of Open Education [J]. Journal of Guangxi Radio and Television University, 2015 (02): 29-32. (In Chinese)

[5] Xie Shengyong, Jiang Xiaoqing and so on. Handbook of Teaching and Educational Administration in Open University [M]. Beijing: Open University pf China Press, 2010.149-150. (In Chinese) 